\title{
Life style factors associated with the risk of type 2 diabetes mellitus
}

Bikash Shrestha ${ }^{1}, \mathrm{MD}$; Bipin Nepal2 ${ }^{2}, \mathrm{MD}$; Yagya Laxmi Shakya ${ }^{3}, \mathrm{MD}$; Binaya Regmi ${ }^{4}, \mathrm{MD}$ ${ }^{1}$ Department of Family Medicine and Wellness, Grande International Hospital, Dhapasi, Kathmandu, Nepal

${ }^{2}$ Department of Transfusion Medicine, Grande International Hospital, Dhapasi, Kathmandu, Nepal

${ }^{3}$ Department of General Practice and Emergency Medicine, TUTH, Kathmandu, Nepal

${ }^{4}$ Department of Internal Medicine, Grande International Hospital, Dhapasi, Kathmandu, Nepal

Corresponding author

Bikash Shrestha, MD

Email: dr.bikashshrestha@gmail.com

Received 28 July 2019

Accepted 7 Oct 2019

\section{ABSTRACT}

\section{Introduction:}

Type 2 diabetes mellitus is the commonest form of diabetes affecting more than $90 \%$ of the diabetic population worldwide. The prevalence of type 2 diabetes and its complications are increasing in the world, including developing nations like Nepal. This study aimed to determine the association between the lifestyle risk factors and the risk of type 2 diabetes mellitus in Nepalese population.

\section{Methods:}

This is hospital based cross sectional observational study done in the urban area of Nepal. Records of clients coming for the general health checkup in Grande International Hospital were evaluated in this study. Comparisons of the lifestyle factors in participants having and not having type 2 diabetes mellitus were done.

\section{Results:}

Significant associations with diagnosis of diabetes mellitus (DM) type 2 were seen in age $(P \leq 0.001)$, associated hypertension $(P \leq 0.001)$, dyslipidemia, family history of $D M(P \leq 0.001)$, alcohol use ( $P$ $\leq 0.001)$, and tobacco use $(P \leq 0.001)$. Logistic regression analysis showed that the odds of having diabetes were high in age group above 40 (OR $-6.9, \mathrm{Cl} 3.82-12.47$ ), history of hypertension (OR$3.84, \mathrm{Cl} 2.42-6.08$ ), tobacco users (OR-2.26, $\mathrm{Cl} 1.12-4.53)$, alcohol users (OR-3.99, $\mathrm{Cl} 2.47-6.44$ ), family history of DM (OR-2.44, Cl $1.53-3.89)$, and abdominal obesity in both males $(\mathrm{OR}-3.9, \mathrm{Cl} 2$ - 7.4) and females (OR-9.6, Cl 3.78-24.35).

\section{Conclusions:}

The modifiable risk factors - obesity, smoking and alcohol use carry significant risks of developing type 2 diabetes. These red flag signs call for urgent attention to look for and rectify the modifiable risk factors in Nepalese population to prevent diabetes.

Keywords: Complications, diabetes mellitus, lifestyle factors, obesity

\section{Introduction}

Type 2 diabetes mellitus is the commonest form of diabetes affecting more than $90 \%$ of the diabetic population worldwide ${ }^{1}$. Reports show that Asian populations with diabetes tend to have prolonged complications ${ }^{2}$. In 2015, there were 526,000 cases of diabetes in $\mathrm{Nepal}^{3}$.
Type 2 Diabetes is associated with obesity, which is significantly seen in developing countries ${ }^{4}$. Inappropriate life style behaviors in recent years have increased the risk of acquiring diabetes ${ }^{5}$. This disease also has a high degree of health and financial burden ${ }^{6}$. It increases risk for cardiovascular diseases $^{7}$ and depression, resulting in low quality 
of life ${ }^{8}$. Proper lifestyle changes and adequate treatment are the keys to decelerate the occurrence of the complications ${ }^{9}$. Intervention programs for healthier lifestyle like weight maintenance, regular physical activity and quitting smoking and alcohol are the cost effective key factors to manage type 2 diabetes ${ }^{10,11}$. This study aims to determine the association between the lifestyle risk factors and type 2 diabetes.

\section{Methods}

This study is a hospital based cross sectional, observational study done in the urban area of Nepal. Target groups

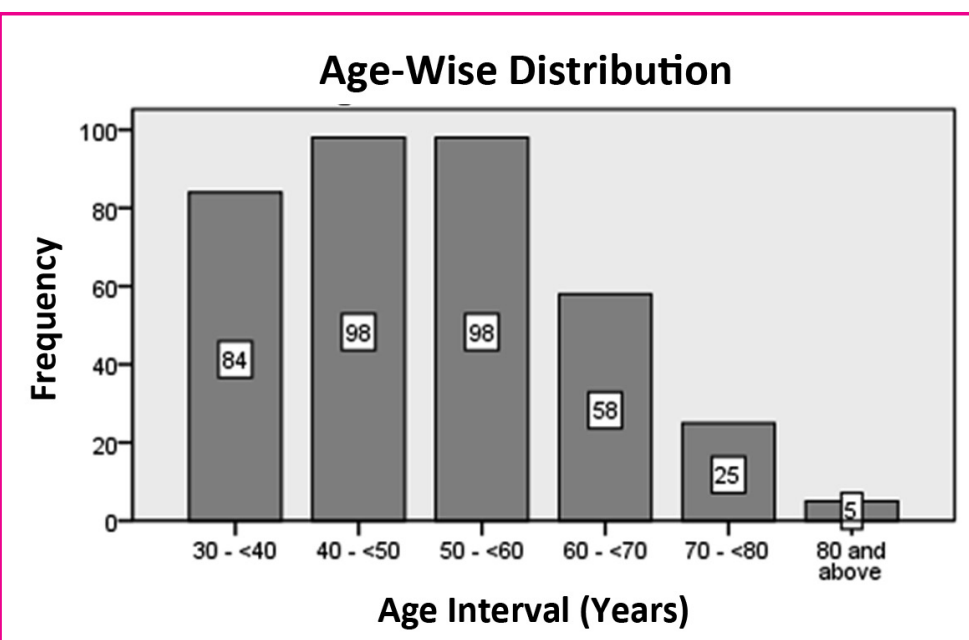

Figure 1: Age-Wise Distribution of this study are the clients visiting the hospital for general health checkup at a tertiary care hospital, Grande International Hospital Wellness Center. The medical records of the clients evaluated between January 2014 and December 2015 were reviewed. The sample size of 250 was calculated from the pilot study done in Wellness Center in Grande International Hospital.

\section{Selection of participants}

Candidates were enrolled from the records of the Wellness Center of the hospital who met the inclusion criteria.

\section{Inclusion Criteria:}

Nepalese, aged 30 years or above seeking general health checkup.

\section{Exclusion Criteria:}

Patients with pre-existing multiple comorbidities like chronic heart failure, chronic liver disease, rheumatological conditions, malignancies or pregnancy.

Body Mass Index classification was done according to the "Asian Criteria"19 as shown in Table 1.

\section{Data Extraction and Analysis}

Clinical and biochemical laboratory results were taken from the patient record books. Statistical analysis was done in SPSS version 20. Descriptive statistics was performed followed by Chi square test for categorical variables. Regression analysis was performed to assess the association between the exposure variables and risk of type 2 diabetes. $p$ value $<0.05$ was considered statistically significant. Results
Total of 368 people participated in the study. Age wise distribution in the bar diagram (Figure 1) showed that most of the participants are in age group of $40-<50$ and $50-<60$ years. The mean age of participant was $50 \pm 12.53$ years.

Sociodemographic characteristics and correlates between those who have and those who don't have diabetes along with p-values are shown in Table 2. A significant association was observed between the groups with regards to age.

In 368 participants, $45.65 \%$ were females. Genderwise, $57.6 \%$ of diabetic and $51.1 \%$ of nondiabetic were males. The association between the gender groups was not significant $(p=0.2)$ (Table 2).

Body Mass Index (BMI) calculation showed that nearly $52 \%$ of the participants were pre-obese according to "Asian Criteria" for BMI and nearly $20 \%$ were obese as shown in the Table 1.

Table 1: Asian Criteria for Classification of BMI of the clients evaluated.

\begin{tabular}{|l|c|c|c|}
\hline \multicolumn{1}{|c|}{ Status } & BMI (kg/m²) & $\begin{array}{c}\text { Fre- } \\
\text { quency }\end{array}$ & $\begin{array}{c}\text { Percen- } \\
\text { tage }\end{array}$ \\
\hline Underweight & $<18.5$ & 3 & 0.82 \\
\hline Normal & $18.5-22.9$ & 40 & 10.87 \\
\hline Overweight & $23-24.9$ & 61 & 16.58 \\
\hline Pre-Obese & $25-29.9$ & 191 & 51.90 \\
\hline Obese & $\geq 30$ & 73 & 19.84 \\
\hline & Total: & 368 & 100.00 \\
\hline
\end{tabular}


Overweight or Obesity was present in $92.9 \%$ of diabetics and in $83.7 \%$ of non-diabetics. Statistically significant association was seen between the groups ( $P=0.006)$ (Table 2$)$.

Abdominal obesity was assessed by waist circumference. In males, mean waist circumference was $93.55 \pm 8.3 \mathrm{~cm}$ and in females, it was $89.57 \pm 11.60 \mathrm{~cm}$. Abdominal obesity was more prevalent in females (72.6\% vs $67.5 \%)$.

Regarding history of comorbidities, $35.33 \%$ of participants had history of hypertension and $22.01 \%$ had history of dyslipidemia. Comparing the groups regarding associated comorbid conditions, $50 \%$ of the diabetics had hypertension whereas only $20.7 \%$ had hypertension in non-diabetic group. There was statistically significant association between the groups regarding associated hypertension ( $P \leq 0.001)$. Dyslipidemia was present in $32.6 \%$ of diabetics and $11.4 \%$ of non-diabetics. Highly significant association was seen between the groups $(P \leq 0.001)$ (Table 2$)$.

Diabetes in first degree relatives was seen in $29.08 \%$ of all participants (38\% of diabetics and $20.1 \%$ of non-diabetics). Result showed statistically significant association with regards to family history of diabetes in $1^{\text {st }}$ degree relatives $(P \leq 0.001)$ (Table 2 ). Nearly $11 \%$ of participants were found to use tobacco products (smoking or chewing) and 31.52\% reported drinking alcohol. History of tobacco use (smoking or chewing tobacco) was present in $14.7 \%$ of diabetics and $7.1 \%$ of non-diabetics. Statistically significant association was seen between the groups ( $P=0.019)$. History of alcohol use was present in $45.7 \%$ of diabetics and $17.4 \%$ of nondiabetics. Highly significant association was also seen between the groups regarding alcohol use ( $P$ $\leq 0.001$ ).

Physical activity was divided into light (doing daily activity) and moderate (doing aerobic activity at least half hour per day). Most of the participants did only light physical activities (73.37\%). In nondiabetics group, light activity was done by $76.6 \%$ and in diabetics group $70.1 \%$ did the light activity. There was no significant association between the groups with regards to physical activities $(P=0.157)$ (Table 2 ). Regarding occupation, $32.6 \%$ were involved in jobs, $24 \%$ were involved in business. Fifty percent of female participants were housewives.

The sample statistics were analyzed using the binary logistic regression model. The results of odds ratio, $p$-value and confidence intervals are shown in the Table 3.Analysis of age category showed that the odds of having type 2 diabetes in 'above 40' group is 6.9 compared to below 40 age group. Regarding gender, males have higher odds of having diabetes than females.

Table 2: Sociodemographic Characteristics and other correlates between cases and controls

\begin{tabular}{|c|c|c|c|c|c|}
\hline Characteristics & Group & Diabetics & Non-diabetics & Total & p-value \\
\hline Gender & $\begin{array}{c}\text { Male } \\
\text { Female }\end{array}$ & $\begin{array}{c}106 \\
78\end{array}$ & $\begin{array}{l}94 \\
90\end{array}$ & $\begin{array}{l}200 \\
168\end{array}$ & 0.209 \\
\hline Age (years) & $\begin{array}{l}\text { Up to } 40 \\
\text { Above } 40\end{array}$ & $\begin{array}{c}73 \\
111 \\
\end{array}$ & $\begin{array}{c}16 \\
168 \\
\end{array}$ & $\begin{array}{c}89 \\
279 \\
\end{array}$ & $\leq 0.001$ \\
\hline BMI $\left(\mathrm{kg} / \mathrm{m}^{2}\right)$ & $\begin{array}{l}\text { Up to } 22.9 \\
23 \text { or more }\end{array}$ & $\begin{array}{c}30 \\
154\end{array}$ & $\begin{array}{c}13 \\
171\end{array}$ & $\begin{array}{c}43 \\
325\end{array}$ & 0.006 \\
\hline Hypertension & $\begin{array}{l}\text { Yes } \\
\text { No }\end{array}$ & $\begin{array}{l}92 \\
92\end{array}$ & $\begin{array}{c}38 \\
146 \\
\end{array}$ & $\begin{array}{l}130 \\
238 \\
\end{array}$ & $\leq 0.001$ \\
\hline Dyslipidemia & $\begin{array}{l}\text { Yes } \\
\text { No }\end{array}$ & $\begin{array}{c}60 \\
124\end{array}$ & $\begin{array}{c}21 \\
163\end{array}$ & $\begin{array}{c}81 \\
287\end{array}$ & $\leq 0.001$ \\
\hline Tobacco Use & $\begin{array}{l}\text { Yes } \\
\text { No }\end{array}$ & $\begin{array}{c}27 \\
157 \\
\end{array}$ & $\begin{array}{c}13 \\
171 \\
\end{array}$ & $\begin{array}{c}40 \\
328\end{array}$ & 0.019 \\
\hline Alcohol & $\begin{array}{l}\text { Yes } \\
\text { No }\end{array}$ & $\begin{array}{c}84 \\
100\end{array}$ & $\begin{array}{c}32 \\
152 \\
\end{array}$ & $\begin{array}{l}116 \\
252 \\
\end{array}$ & $\leq 0.001$ \\
\hline Physical Activity & $\begin{array}{c}\text { Light } \\
\text { Moderate }\end{array}$ & $\begin{array}{c}141 \\
43\end{array}$ & $\begin{array}{c}129 \\
55\end{array}$ & $\begin{array}{c}270 \\
98 \\
\end{array}$ & 0.157 \\
\hline Family history of Diabetes & $\begin{array}{l}\text { Yes } \\
\text { No }\end{array}$ & $\begin{array}{c}70 \\
114\end{array}$ & $\begin{array}{c}37 \\
147\end{array}$ & $\begin{array}{l}107 \\
261\end{array}$ & $\leq 0.001$ \\
\hline
\end{tabular}


Hypertension is seen to be a statistically significant factor. The odds of having diabetes in people with history of hypertension is 3.84 compared to those without history of hypertension $(\mathrm{Cl}=2.42-6.08)$ (Table 3). People who use tobacco, the odds of having diabetes is 2.26 times than people who don't use tobacco and is statistically significant $(\mathrm{Cl}=1.12-$ 4.53). Alcohol use was also found to be a significant factor with the odds of 3.99 times $(\mathrm{Cl}=2.47-6.44)$.

In the physical activity category, although the association between the groups is not statistically significant, the odds of having diabetes is 1.4 times more in people doing light exercise than the group doing moderate intensity exercises $(\mathrm{Cl}=0.87-$ 2.22) (Table 3). Though overweight and obesity are not found to be significant factors, results show that as the weight increases, the risk of diabetes also increases. In overweight group the odds of having diabetes is $1.9(\mathrm{Cl} 0.04-6)$ where as in pre-obese and obese group the odds of having diabetes is $2.29(\mathrm{Cl} 0.038-5)$. The odds of having diabetes is $3.9(\mathrm{Cl} 2-7.4)$ in males, and $9.6(\mathrm{Cl}$ $3.78-24.35$ ) in females when abdominal obesity is taken into account (Table 3 ). Having a family history of diabetes has higher odds of having diabetes than without the family history (OR 2.44; $\mathrm{Cl} 1.53-3.89$ ).

Comparing the occupation, the odds of having diabetes in clients in business, housewives and jobholders is low compared to those who don't do any occupation, odds ratio $0.47,0.48$ and 0.23 respectively (Table 3 ).

\section{Discussion}

The prevalence of Type 2 Diabetes and its complications is increasing and is one of the most important preventable health burdens in the world. Modifiable risk factors like weight, smoking, alcohol, physical activity, and hypertension were analyzed in this study. The results showed that the group above 40 years of age has higher odds of

Table 3: Distribution of variables: Binary Logistic Regression Analysis

\begin{tabular}{|c|c|c|c|}
\hline Characteristics & Category & Odds Ratio (OR) & Confidence Interval (CI) \\
\hline Age (years) & $\begin{array}{c}\text { Upto } 40 \\
\text { Above } 40\end{array}$ & $\begin{array}{c}1 \\
6.9 \\
\end{array}$ & $3.82-12.47$ \\
\hline Gender & $\begin{array}{l}\text { Female } \\
\text { Male }\end{array}$ & $\begin{array}{c}1 \\
1.3 \\
\end{array}$ & $0.86-1.96$ \\
\hline BMI (Asian Criteria) & $\begin{array}{c}<18.5 \\
18.6-22.9 \\
23-24.9 \\
25-29.9 \\
30 \text { or more }\end{array}$ & $\begin{array}{c}1 \\
0.857 \\
1.935 \\
2.292 \\
2.294 \\
\end{array}$ & $\begin{array}{l}0.07-10.37 \\
0.16-22.48 \\
0.20-25.70 \\
0.19-26.42\end{array}$ \\
\hline $\begin{array}{l}\text { Waist Circumference } \\
\text { (Male) }\end{array}$ & $\begin{array}{c}\text { Upto } 90 \mathrm{~cm} \\
\text { More than } 90 \mathrm{~cm}\end{array}$ & $\begin{array}{c}1 \\
3.9 \\
\end{array}$ & $2-7.4$ \\
\hline $\begin{array}{l}\text { Waist Circumference } \\
\text { (Female) }\end{array}$ & $\begin{array}{c}\text { Upto } 80 \mathrm{~cm} \\
\text { More than } 80 \mathrm{~cm}\end{array}$ & $\begin{array}{c}1 \\
9.6 \\
\end{array}$ & $3.78-24.35$ \\
\hline Occupation & $\begin{array}{c}\text { No } \\
\text { Business } \\
\text { Housewife } \\
\text { Jobholder }\end{array}$ & $\begin{array}{c}1 \\
0.473 \\
0.487 \\
0.238 \\
\end{array}$ & $\begin{array}{c}0.24-0.9 \\
0.25-0.93 \\
0.12-0.44\end{array}$ \\
\hline History of Hypertension & $\begin{array}{l}\text { No } \\
\text { Yes }\end{array}$ & $\begin{array}{c}1 \\
3.84 \\
\end{array}$ & $2.42-6.08$ \\
\hline Tobacco Use & $\begin{array}{l}\text { No } \\
\text { Yes }\end{array}$ & $\begin{array}{c}1 \\
2.26 \\
\end{array}$ & $1.12-4.53$ \\
\hline Alcohol Use & $\begin{array}{l}\text { No } \\
\text { Yes }\end{array}$ & $\begin{array}{c}1 \\
3.99 \\
\end{array}$ & $2.47-6.44$ \\
\hline Physical Activity & $\begin{array}{l}\text { Moderate } \\
\text { Light }\end{array}$ & $\begin{array}{c}1 \\
1.4\end{array}$ & $0.87-2.22$ \\
\hline Family History of Diabetes Mellitus & $\begin{array}{l}\text { No } \\
\text { Yes }\end{array}$ & $\begin{array}{c}1 \\
2.44\end{array}$ & $1.53-3.89$ \\
\hline
\end{tabular}


having diabetes. The finding is similar to the result of the study done by Balakrishnan et al. ${ }^{1}$ which showed that the group above 50 years of age had five fold chance to get diabetes when compared to those of the 20-30 age group. Another study done in rural India by Barik et al. in 2016 also demonstrated that the probability of diabetes is higher as the age advances $^{14}$. Similarly, another study done in Guilin, China by Zou et al. found that the incidence of type 2 diabetes was significantly higher in participants aged $>51.5$ years $(9.5 \%)$ compared to participants aged $\leq 51.5$ years $(2.1 \%)$. In addition to Chinese population, the people in USA and Africa also show similar trend that advanced age is a risk factor for type 2 diabetes, and that the prevalence of type 2 diabetes increases with age ${ }^{18}$. In the study done by Papier et al. from Thailand, the age-sex specific cumulative incidences of diabetes between 2005 and 2013 were analyzed. The study showed that the incidence rose with age for both sexes, almost exponentially for men from age 50 years ${ }^{15}$.

The odds of having diabetes is 2.29 with overweight or obesity. In the presence of abdominal obesity, the odds are even higher. In males with abdominal obesity, the odds of having diabetes is 3.9 whereas in females it is 9.6 (nearly 3 times higher than in the males). Findings in this study is similar to various studies done in different countries like Thailand in which type 2 diabetes increased significantly for both sexes with increasing $\mathrm{BMI}^{15}$. Similarly in Tanzania, overweight or obesity status had an independent prevalence risk ratio for glucose impairment $(2.16 ; 95 \% \mathrm{Cl} 1.39-3.36)^{12}$. Another study in India showed that compared to people with normal body mass index, overweight/obese people are more prone to being diagnosed with diabetes ( $\beta$ : $0.388 ; 95 \% \mathrm{Cl} 0.147$ to 0.628$)^{14}$. Two studies done in China showed that overweight or obesity is one of the major risk factors for type 2 diabetes ${ }^{17,18}$. A study done in contemporary population of the Framingham Study showed that the risk of type 2 diabetes increased significantly with increase in obese-years. Body mass index (BMI) was multiplied by the number of years lived with obesity at that BMI to define the number of obese-years ${ }^{20}$.

The odds of having diabetes is 1.4 times more in participants doing light exercise as compared to people doing moderate exercise. The study done in Nepal by Vaidya et al. ${ }^{13}$ in 2014 showed that the participants with diabetes had increased odds for less physical activity as compared to the non- diabetics. Another study done in Peru in 2016 also showed that the people doing moderate or high physical activity had lower risk of having diabetes $^{21}$. The study done in China showed that the participants who are physically active 5-7 days per week are at low risk of developing pre-diabetes as compared to those who had physical activity less than 1 day per week ${ }^{17}$.

Regarding tobacco use, this study showed the odds of having diabetes is high in those who use tobacco. This finding is consistent with the results of study done in India which showed the odds of having diabetes is 2.49 times high in the tobacco users and similar findings was also seen in the study done by Kawakami et al. which showed that the risk of developing type 2 diabetes is 3.27 times higher in those smokers who used $16-26$ cigarettes per day as compared to non-smokers ${ }^{1,22}$. Another lifestyle factor, Alcohol use was also found to be the significant factor in this study which is in contrast to the findings that were seen in other developing countries. The odds of having diabetes in people who use alcohol was 3.99 times. The finding is in contrast with the study done by Stanifer et al. in 2016 which showed that the individuals with glucose impairment were less likely to be consuming alcohol $^{12}$. The study done by Bernabé-Ortiz et al. also didn't show the significant difference regarding alcohol as a risk of type 2 diabetes ${ }^{21}$. Another study done in rural India by Barik et al. also didn't show the significant association as a risk factor for type 2 diabetes ${ }^{14}$. But results of this study is consistent with the study done in Thailand in which increased risk of type 2 diabetes was observed among men who consumed alcohol regularly ${ }^{15}$.

Regarding comorbidities, Hypertension is one of the strong and independent risk factors for diabetes mellitus. In this study, the odds of having diabetes in people with a history of hypertension are 3.84 times more as compared to the people without history of hypertension. The findings are similar to the study done across the world. The study done by Stanifer et al. in Tanzania also observed high prevalence of hypertension in adults with diabetes ${ }^{12}$. A crosssectional study done by Zou et al. in Guilin, China also showed that hypertension was one of the significant influencing factors for type 2 diabetes ${ }^{18}$. The study comparing the cardiovascular disease risk factors in diabetic and non-diabetic subjects in Iran found that the subjects with diabetes had higher systolic and diastolic blood pressure ${ }^{23}$. 
Family history of diabetes is another strong risk factor for acquiring diabetes. This study showed that the participants having family history of diabetes had higher odds of having diabetes as compared to those who don't have family history of diabetes (OR 2.44; $\mathrm{Cl} 1.53-3.89)$. The study result is similar to that of the study done in other countries. In India, a study done in North Kerala observed that the participants with family history of type 2 diabetes had 3.09 fold greater chance of getting the disease ${ }^{1}$. Another study done in Punjab by Tripathy et al. also found that positive family history had 1.4 time more odds of having diabetes ${ }^{16}$.

\section{Conclusions}

Increasing prevalence of type 2 diabetes is already stretching scarce resources in developing countries like Nepal where communicable diseases are major burden of public health system. The modifiable risk factors - obesity, smoking and alcohol use carry significant risks of developing type 2 diabetes. These red flag signs call for urgent attention to look for and rectify the modifiable risk factors in Nepalese population to prevent diabetes.

\section{References}

1. Valliyot B, Sreedharan J, Muttappallymyalil J, Valliyot SB. Risk factors of type 2 diabetes mellitus in the rural population of north kerala, India: a case control study. Diabetol Croat. 2013;42(1):33-40.

2. Hu M, Wan Y, Yu L, Yuan J, Ma Y, Hou B, et al. Prevalence, Awareness and Associated Risk Factors of Diabetes among Adults in Xi'an, China. Sci Rep. 2017;7(1):10472.

3. International Diabetic Foundation. http:// www.idf.org/membership/sea/nepal.

4. Sonomtseren S, Sankhuu $Y$, Warfel JD, Johannsen DL, Peterson CM, Vandanmagsar B. Lifestyle modification intervention improves glycemic control in Mongolian adults who are overweight or obese with newly diagnosed type 2 diabetes. Obes Sci Pract. 2016;2(3):303-8.

5. Gyawali B, Sharma R, Neupane D, Mishra SR, van Teijlingen E, Kallestrup P. Prevalence of type 2 diabetes in Nepal: a systematic review and meta-analysis from 2000 to 2014. Glob Health Action. 2015;8(1):29088.
6. Silva EFF, Ferreira CMM, Pinho L. Risk factors and complications in type 2 diabetes outpatients. Rev Assoc Med Bras. 2017;63(7):621-7.

7. Pandey AR, Karki KB, Mehata S, Aryal KK, Thapa $P$, Pandit A, et al. Prevalence and Determinants of Comorbid Diabetes and Hypertension in Nepal: Evidence from Non Communicable Disease Risk Factors STEPS Survey Nepal 2013. J Nepal Health Res Counc. 2015;13(29):20-5.

8. Huang $\mathrm{CY}$, Lai $\mathrm{HL}, \mathrm{Lu} Y \mathrm{YC}$, Chen WK, Chi SC, $\mathrm{Lu} C Y$, et al. Risk Factors and Coping Style Affect Health Outcomes in Adults With Type 2 Diabetes. BIOL RES NURS.2016;18(1):82-9.

9. Nerat T, Locatelli I, Kos M. Type 2 diabetes: cost-effectiveness of medication adherence and lifestyle interventions. Patient Prefer Adherence. 2016;10:2039-49.

10. Nguyen CT, Pham NM, Tran DV, Lee AH, Binns $\mathrm{CW}$. Lifestyle and diet in relation to risk of type 2 diabetes in Vietnam: a hospital-based casecontrol study. SpringerPlus. 2016;5(1):687.

11. Folling IS, Solbjor $M$, Midthjell $K$, Kulseng $B$, Helvik AS. Exploring lifestyle and risk in preventing type 2 diabetes-a nested qualitative study of older participants in a lifestyle intervention program (VEND-RISK). BMC public health. 2016;16(1):876.

12. Stanifer JW, Cleland CR, Makuka GJ, Egger $J R$, Maro V, Maro $\mathrm{H}$, et al. Prevalence, Risk Factors, and Complications of Diabetes in the Kilimanjaro Region: A PopulationBased Study from Tanzania. PLoS One. 2016;11(10):e0164428.

13. Vaidya A, Krettek A. Physical activity level and its sociodemographic correlates in a periurban Nepalese population: a cross-sectional study from the Jhaukhel-Duwakot health demographic surveillance site. International Journal of Behavioral Nutrition and Physical Activity. 2014;11(1):39.

14. Barik A, Mazumdar S, Chowdhury A, Rai RK. Physiological and behavioral risk factors of type 2 diabetes mellitus in rural India. BMJ open diabetes research \& care. 2016;4(1):e000255. 
15. Papier K, Jordan S, D'Este C, Bain C, Peungson $J$, Banwell C, et al. Incidence and risk factors for type 2 diabetes mellitus in transitional Thailand: results from the Thai cohort study. BMJ open. 2016;6(12):e014102.

16. Tripathy JP, Thakur JS, Jeet G, Chawla S, Jain $S$, Pal A, et al. Prevalence and risk factors of diabetes in a large community-based study in North India: results from a STEPS survey in Punjab, India. Diabetol Metab Syndr. 2017;9:8.

17. Zhao $M$, Lin $H$, Yuan $Y$, Wang $F, X i Y$, Wen $L M$, et al. Prevalence of Pre-Diabetes and Its Associated Risk Factors in Rural Areas of Ningbo, China. Int J Environ Res Public Health. 2016;13(8).

18. Zou D, Ye Y, Zou N, Yu J. Analysis of risk factors and their interactions in type 2 diabetes mellitus: A cross-sectional survey in Guilin, China. J Diabetes Investig. 2017;8(2):188-94.

19. O.Llido L, Mirasol R. Comparison of Body Mass Index based nutritional status using WHO criteria versus "Asian" criteria: report from the Philippines. JPEN J Parenter Enteral Nutr. 2011:1-8.
20. Abdullah A, Amin FA, Hanum F, Stoelwinder $J$, Tanamas $S$, Wolf $R$, et al. Estimating the risk of type-2 diabetes using obese-years in a contemporary population of the Framingham Study. Global health action. 2016;9(1):30421.

21. Bernabe-Ortiz A, Carrillo-Larco RM, Gilman RH, Checkley W, Smeeth L, Miranda JJ, et al. Contribution of modifiable risk factors for hypertension and type-2 diabetes in Peruvian resource-limited settings. J Epidemiol Community Health. 2016;70(1):4955.

22. Kawakami N, Takatwuka N, Shimizu H, Ishibarshi $\mathrm{H}$. Effect of smoking on the incidence of NIDDM. Replication and extension in a Japanese cohort of male employee. Am J Epidemiol. 1997;145:103-9.

23. Niroumand $S$, Dadgarmoghaddam $M$, Eghbali B, Abrishami M, Gholoobi A, Bahrami Taghanaki HR, et al. Cardiovascular Disease Risk Factors Profile in Individuals With Diabetes Compared With Non-Diabetic Subjects in North-East of Iran. Iran Red Crescent Med J. 2016;18(8):e29382. 